\title{
Aspectos do verso e sua crise nas retraduções brasileiras de Un coup de dés, de Stéphane Mallarmé
}

\section{Aspects of the verse and its crisis in Brazilian retranslations of Stéphane Mallarmé's Un coup de dés}

Henrique Provinzano Amaral ${ }^{*}$

\author{
[...] \\ mas eis que \\ teu olhar \\ encontra o dele \\ (Mallarmé) que \\ ali \\ do fundo \\ da morte \\ olha
}

Ferreira Gullar, "Fotografia de Mallarmé”

Au traitement, si intéressant, par la versification subi, de repos et interrègne, gît, moins que dans nos circonstances mentales vierges, la crise.

Stéphane Mallarmé, «Crise de vers »

* Departamento de Letras Modernas da USP, Área de Estudos Linguísticos, Literários e Tradutológicos em Francês. E-mail: amaralhenriquep@gmail.com 
Resumo: Este artigo se dedica à leitura crítica de duas traduções brasileiras do célebre poema mallarmeano Um lance de dados [Un coup de dés, 1897], assinadas por Haroldo de Campos e Álvaro Faleiros e publicadas pela primeira vez, respectivamente, em 1974 e 2013. Como mote de nossa análise, buscamos retomar aspectos da reflexão de Stéphane Mallarmé em torno da ideia de verso, levando em consideração elementos da história literária e de parte do debate que aquele notável assunto suscitou no século XIX francês. Nesse contexto, ganha relevo especial o texto "Crise de vers", constante do volume mallarmeano das Divagations (1897). Por fim, confrontamos algumas das soluções de tradução adotadas por cada tradutor, com o intuito de arrazoar um juízo crítico possível dessas reescritas tradutórias em meio à anterior discussão sobre o verso e sua crise.

Palavras-chave: Stéphane Mallarmé; Um lance de dados; Haroldo de Campos; Álvaro Faleiros; retradução.

Abstract: This article focuses on a critical reading of two Brazilian translations of Stéphane Mallarmé's A throw of the dice [Un coup de dés, 1897], signed by Haroldo de Campos and Álvaro Faleiros and published for the first time, respectively, in 1974 and 2013. As a leitmotiv of our analysis, we seek to resume aspects of Mallarmé's thought about the idea of verse, taking into account elements of literary history and part of the debate that this subject raised in the $19^{\text {th }}$ century in France. In this context, gains special emphasis the famous text "Crisis of verse" [Crise de vers], contained in the Mallarmean volume of the Divagations (1897). Finally, we compare some of the translation solutions adopted by each Brazilian translator, in order to achieve a critical reasoning of these translational rewritings in front of the previous discussion of verse and its crisis.

Keywords : Stéphane Mallarmé ; A throw of the dice ; Haroldo de Campos ; Álvaro Faleiros ; retranslation. 
A edição da segunda tradução brasileira do célebre poema mallarmeano Um lance de dados [Un coup de dés], realizada por Álvaro Faleiros e publicada pela primeira vez em 2013, contém um notável aparato crítico, no qual se inclui um ensaio intitulado "Traduzir Mallarmé é o lance de dados" (SISCAR 2017). Neste texto, o crítico Marcos Siscar discute alguns aspectos dessa tradução, confrontando-a à primeira que o texto de Stéphane Mallarmé havia recebido no Brasil - a também célebre tradução de Haroldo de Campos, que veio a público em 1974. Conforme indica sua história editorial, tal ensaio manifesta certa aderência ao projeto retradutório ${ }^{1}$ de Faleiros e elogia, por exemplo, as estratégias que este último emprega para "humanizar" o poema, "retirando-o do maquinário concretista no qual funciona como um dos dispositivos, aliás de destacada importância" (SISCAR 2017: 20). Siscar observa, ademais, que Faleiros "distingue termos confundidos pela tradução de Haroldo de Campos, refaz o traçado de determinadas metáforas, adota soluções menos glamourosas para nossos hábitos poéticos [...]. a fim de enfatizar a percepção das contrariedades do poema" (2017: 21-22).

Tais considerações, a nosso ver bastante acertadas, fazem eco a um bom número de críticas - dirigidas ao poeta concretista e seus colegas de grupo, Augusto de Campos e Décio Pignatari -, as quais incidem sobre o modo como estes costumam lidar com a teoria e a prática da tradução, em diálogo com as múltiplas historicidades contidas na história literária e sua necessidade de atualização. Anota o crítico:

No texto de Un coup de dés assinado por Haroldo, as opções do trabalho de tradução [...] encontram justificativa em uma ideia da práxis poética formulada em "Por uma poética sincrônica" [...]; ou já no artigo "Da Tradução como Criação e como Crítica" [...], com o auxílio de princípios teóricos formalistas e estruturalistas. Ali, a história literária é subordinada a um ponto de vista contemporâneo sobre o valor poético, gesto que produz e legitima ostensivamente a sinonímia entre o sentido

\footnotetext{
${ }^{1}$ Empregamos, aqui, o conceito de retradução tal como desenvolvido por Faleiros e Mattos (2017).
} 
da tradição e a "estratégia" poética e política do presente. 0 resultado dessa visão tradutória baseada na criatividade dos recursos expressivos e nas soluções poeticamente "válidas" em português dá destaque, naquele caso, aos problemas de macroestrutura visual e sintática, e aos problemas léxicos e morfológicos ligados à valorização do significante [...]. (SISCAR 2017: 12)

O trecho dá vazão à principal ressalva levantada por Siscar ao projeto tradutório encampado por Haroldo, o que se alimenta de e alimenta - conforme as correspondências delineadas num dos artigos haroldianos lembrados pelo crítico, "Da tradução como Criação e como crítica” (CAMPOS 1974) - a noção concretista de poética sincrônica. Em oposição a esta, são fortemente condenados a subordinação da história literária “a um ponto de vista contemporâneo sobre o valor poético", assim como, por extensão, o "gesto que produz e legitima ostensivamente a sinonímia entre o sentido da tradução e a ‘estratégia’ poética e política do presente” (SISCAR 2017: 12). Trata-se, pois, de uma espécie de discordância de princípios relativa a um determinado modo de conceber e praticar a atividade tradutória (e, portanto, conforme Haroldo, crítica e criativa) que não resulta sem consequências no plano das suas relações com os campos da história, da filosofia e mesmo de certa antropologia.

Em que pese a complexidade e perspicácia de tal crítica, de nível bastante abstrato, o ensaio de Siscar não se debruça sobre muitos dos aspectos textuais da tradução haroldiana de Um lance de dados, os quais nos parecem merecer um esforço mais detido de análise e interpretação. Ademais, se é verdade que o grupo dos poetas concretistas de São Paulo sempre enfatizou seu caráter coletivo, uma recusa por princípio e em bloco de seu projeto tradutório poderia levar ao apagamento de sutilezas das numerosas e variadas "transcriações"2 realizadas por Haroldo e Augusto de Campos, bem como por seu parceiro Décio Pignatari.

É certo que, funcionando na edição mencionada como aparato introdutório à tradução de Faleiros, o ensaio em pauta não teria a obrigação, quiçá nem mesmo o espaço, de analisar em detalhe aquela produzida por

\footnotetext{
${ }^{2}$ Essa terminologia é empregada pelo próprio Haroldo de Campos, por exemplo no artigo "Da Transcriação: poética e semiótica da operação tradutora", publicado pela primeira vez em 1987 e reproduzido no volume Haroldo de Campos - transcriação (NÓBREGA; TÁPIA 2013).
} 
Campos. Todavia, assim como a tradução do primeiro trabalha produtivamente suas objeções e afastamentos em relação à do segundo, o texto de Marcos Siscar não perde de vista, por toda sua extensão, o referido dissenso com as ideias do grupo concretista. Esse é um dos motivos pelos quais o crítico procede a uma revisão, desta vez complexa e detalhada, do projeto criativo visado pelo poeta francês no exercício de escrita de Un coup de dés - outra das faltas diagnosticadas na apreensão que Campos faz de Mallarmé. Numa tentativa de aproximação geral desse projeto, Siscar escreve:

O poema seria uma mistura de prosa e verso livre, que poderia muito bem ser comparado a um dos longos parágrafos da prosa crítica de Divagations (à qual não faltam as interferências dos parênteses, das aposições, das elipses e das inversões). [...] é preciso lembrar que Un coup de dés se insere em um debate já nomeado e analisado pelo próprio Mallarmé a respeito das novas formas do verso, ou da "crise" no verso que, para ele, é crise de verso, ou seja, tem um sentido produtivo de modulação conflituosa dentro do próprio verso, depois do esgarçamento da metrificação tradicional. (SISCAR 2017: 22-23)

É preciso que nos detenhamos sobre o duplo movimento analítico descrito nessa citação. De um lado, o crítico propõe um paralelo entre a linguagem precipitada em Un coup de dés, "uma mistura de prosa e verso livre", e aquela da prosa crítica do volume Divagations (MALLARMÉ 2003; primeira publicação em 1897) - paralelo esse que recai sobre traços estilísticos que seriam comuns a esses textos. De outro, integra tal aproximação ao quadro de um debate mais amplo, "a respeito das novas formas do verso", no qual ganha relevo um intertexto mallarmeano específico, aquele intitulado "Crise de vers", constante do aludido volume. Esse gesto duplo mostra-se fundamental para a perspectiva que buscamos construir aqui, na medida em que autoriza e exige uma aproximação da materialidade do texto, ao mesmo tempo em que situa a discussão num plano mais abrangente, sem com isso perder a atenção sobre elementos microtextuais.

Ora, é justamente esse movimento crítico que talvez possa lançar luz, de nosso ponto de vista, sobre as complexas relações entre aspectos tidos como problemáticos - conforme a leitura de Siscar - na tradução de Um lance de dados assinada por Haroldo de Campos e a necessidade de uma apreensão 
consequente da crise teorizada e encenada nos textos mallarmeanos. Nesse sentido, propomos que a ideia de verso - ou de sua dissolução, do esgarçamento histórico pelo qual passou - funcione como fio condutor da reflexão, alinhavando pontos que levam da obra "original" e sua historicidade própria à consideração de soluções de tradução específicas, ou seja, do projeto poético de Mallarmé às atualizações tradutórias que ele tem suscitado no contexto brasileiro recente.

\section{2.}

O poema, cujo título completo é Un coup de dés jamais n'abolira le hasard, foi publicado pela primeira vez em 1897, numa revista intitulada Cosmopolis, no ano anterior ao da morte de Mallarmé. Desde essa primeira aparição - à qual viria suceder, em 1914, uma versão póstuma dita definitiva - o texto conta com um prefácio deveras sugestivo, no qual chama a atenção o tratamento de certa problemática em torno do verso, sobretudo daquele praticado na França. Já no primeiro período de sua nota, o autor afirma que ela "[...] ensina, ao Leitor hábil, pouca coisa para além de sua penetração [...]"; em seguida, admite que ela "[...] pode perturbar o ingênuo [...]" (Mallarmé 2017: 87) ${ }^{3}$, efeito atribuído a certo aspecto "chocante" do poema, a exemplo do relevo nele conferido aos "brancos", isto é, aos espaços propositalmente não ocupados pela mancha tipográfica.

Não obstante, se a aparência de Un coup de dés pode se mostrar perturbadora à primeira vista, o poeta se esforça, no prefácio, para atenuar essa possível impressão - portanto “[...] os 'brancos', com efeito, assumem importância, chocam de início [...]", no entanto, isso se deve ao fato de que "[...] a versificação os exigiu, como o silêncio ao redor [...]" (MALLARMÉ 2017:

\footnotetext{
3 Optamos por utilizar, no caso das citações do prefácio ao poema, a tradução de Faleiros (MALLARMÉ 2017). Mais adiante neste artigo, quando formos cotejar as soluções apresentadas por cada tradutor, citaremos os trechos originais conforme a edição organizada por Bertrand Marchal (MALLARMÉ 2003).
} 
87). Assim, as linhas que surgem - “[...] um fragmento, lírico ou de poucos pés [...]" (MALLARMÉ 2017: 87) - representam uma “medida” que o autor afirma não transgredir, mas apenas dispersar. Em seguida, Mallarmé (2017: 87) explicita que "[...] não se trata, assim como sempre, de traços sonoros regulares ou versos - antes, de subdivisões prismáticas da Ideia [...]”, de modo que “[...] a distância copiada que mentalmente separa grupos de palavras ou as palavras entre si [...]" leva a "[...] uma visão simultânea da Página: esta tomada por unidade assim como em outra parte o Verso ou linha perfeita".

Em síntese, nesses fragmentos de um prefácio tão breve quanto complexo, está em jogo um esforço de deslocamento da problemática do verso francês para outra parte, ou seja, para um território em que ela seja a um só tempo transposta e rearranjada. Isso porque, enquanto se sustenta que a unidade do poema é a Página, o gênero novo que ele encarna “[...] deixa intacto o antigo verso [...]", ao qual o poeta afirma manter “[...] um culto [...]” e atribuir “[...] o império da paixão e dos devaneios” (MALLARMÉ 2017: 88). A tomada de partido é, aqui, no mínimo controversa, sendo que algumas afirmações - a exemplo de “[t]erei, contudo, indicado do Poema anexo, mais do que o esboço, um 'estado' que não rompe em todos os pontos com a tradição" (MALLARMÉ 2017: 88) - desafiam claramente uma tendência a certa leitura vanguardista, que vê nesse texto um epítome da lógica da ruptura. Ainda assim, o receio flagrante de "[...] agir por demais contrariamente aos usos" não impede que, ao situar essa obra no leque de suas contemporâneas, Mallarmé (2017: 88) projete aspectos de seu porvir: “[h]oje ou sem presumir o futuro que sairá daqui, nada ou quase uma arte, reconheçamos facilmente que a tentativa faz parte, com imprevistos, de investigações particulares e caras a nosso tempo, o verso livre e o poema em prosa”.

Tal feixe de questões, de grande delicadeza e complexidade, foi assim resumido por Sérgio Medeiros, em outro texto pertencente ao aparato crítico da segunda tradução brasileira de Um lance de dados:

Quentin Meillassoux, num estudo curioso e inventivo intitulado Le Nombre et la sirene: Un déchiffrage du Coup de dés de Mallarmé, afirma que o Poema radicaliza aparentemente a entreprise do verso livre. Porém, ao contrário de defender o 
verso livre, ele propõe, segundo Meillassoux, uma nova forma, a qual não é apenas a defesa de um gênero novo, mas, paradoxalmente, a defesa indireta do verso antigo e da rima. (MEDEIROS 2017: 10)

Para Medeiros, portanto, apoiado na leitura de Meillassoux, o problema se enuncia de modo paradoxal, pois a "radicalização da entreprise do verso livre" não advém de sua prática escritural efetiva, mas, ao contrário, de uma "defesa indireta do verso antigo e da rima". Assim, de acordo com essa interpretação - bem como com algumas linhas de força destacadas no prefácio mallarmeano a Um lance de dados -, a "nova forma" ou o "gênero novo" instituídos por esse poema repousariam, no que tange à questão do verso, sobre um paradoxo. Não é o caso aqui, bem entendido, de condenar esse tipo de operação mental, nem mesmo de buscar solucioná-la por meio de uma chave de leitura que pretenda resolvê-la definitivamente; trata-se, de maneira inversa, de integrar esse paradoxo no quadro de uma "crise de verso", ou seja, para retomar citação anterior de Siscar (2017: 23), de algo que "tem um sentido produtivo de modulação conflituosa dentro do próprio verso, depois do esgarçamento da metrificação tradicional”.

No Livro Mallarmé: la grammaire et le grimoire, Mireille Rupli et Sylvie Thorel-Cailleteau levam a cabo uma instigante análise do lugar ocupado pelo verso e algumas de suas implicações na obra poética e crítica mallarmeana. A certa altura do capítulo "Le vers", as autoras afirmam (2005: 180) que "[o] verso, porque forma uma reflexão da linguagem, realiza assim, absolutamente, o que a língua ordinária ignora e do qual se perdeu todo vestígio [...]: a concordância do som e do sentido, que permite a convocação mágica dos objetos"4. Tal concepção, derivada de uma investigação profunda da e sobre a linguagem, conferiria ao poeta a função de

[...] formatar o material do qual ele dispõe, de fabricar a harmonia esparsa ou desfeita, por meio da linha que recolhe seus restos e os reúne. O verso forma, assim, o reflexo de uma língua harmoniosa, e isso desde as origens, ou em todo caso no

\footnotetext{
4 «Le vers, parce qu'il forme une réflexion du langage, réalise ainsi, absolument, ce que la langue ordinaire ignore et dont on a perdu toute trace [...]: l'accord du son et du sens, qui permet la convocation magique des objets ». Todas as traduções dessa obra foram feitas por nós.
} 
mais próximo possível delas" (RUPPLI; THOREL-CAILLETEAU 2005: $183)^{5}$.

Ora, nessas passagens, entra em cena nitidamente um entendimento do verso que, por força de querer fabricar uma harmonia - a referida concordância entre som e sentido, ou a ficção de uma língua mágica - , acaba distanciandose das concepções convencionais do assunto, ligadas simplesmente a critérios técnicos, tais como a métrica e os acentos presentes nos tratados de versificação. A imagem de uma linha que recolhe os restos do material linguístico e os reúne aparenta estar, a nosso ver, mais próxima dos segmentos frasais de Um lance de dados do que do verso praticado, por exemplo, por Victor Hugo. Contra a poética representada por este, que se pretendia, aliás, uma encarnação da própria poesia, ao mesmo tempo em que fazia dela uma questão meramente técnica, Mallarmé propõe um trabalho de escavação do poema em meio à crise de verso:

A posição de Mallarmé é, assim, extremamente delicada: ao mesmo tempo ele reconhece no verso [...] a necessária ficção de uma língua própria, adequada relativamente, e mede sua extenuação formal, sua vacuidade. Mais do que isso, por ter "cavado o verso" de Hérodiade ao ponto de encontrar o Nada, e porque ele mesmo sofreu o que chamávamos [...] de "tentação da flauta", na esteira de Verlaine, Mallarmé experimentou a emancipação do verso como uma crise dolorosa [...], mas ele deve reconhecer sua parte na história de um evento tão considerável. (RUPPLI; THOREL-CAILLETEAU 2005: 188) ${ }^{6}$

Atravessada por paradoxos, a postura de Mallarmé assim caracterizada oferece novamente uma série de dificuldades aos leitores de anseios simplificadores ou unívocos, pois o reconhecimento da necessidade do verso,

\footnotetext{
5 «Au poète, il revient en conséquence de façonner le matériau dont il dispose, de fabriquer l'harmonie éparse ou défaite, par le moyen de la ligne qui en recueille les débris et les réunit. Le vers forme ainsi le reflet ou la fiction d'une langue harmonieuse, et cela dès les origines, ou au plus près d'elles en tout cas ».

6 « La position de Mallarmé est donc extrêmement délicate : à la fois il reconnait dans le vers [...] la nécessaire fiction d'une langue propre, adéquate relativement, et il en mesure l'exténuation formelle, la vacance. Bien plus, pour avoir "creusé le vers » de Hérodiade au point de trouver le Néant, et parce qu'il a lui-même subi ce qu'on appelait [...] « la tentation de la flûte », dans le sillage de Verlaine, Mallarmé éprouve l'émancipation du vers comme une crise douloureuse [...], mais il doit reconnaitre sa part dans l'histoire d'un évènement si considérable ».
}

TradTerm, São Paulo, v.36, novembro/2020, p. 23-46 www. revistas.usp.br/tradterm 
como espaço de precipitação da referida investigação linguística, dá-se concomitantemente à constatação de seu desgaste formal. A citação reconhece, ademais, na obra anterior do poeta (figurada pelo poema Hérodiade) e nas relações que ele mantinha com outros autores contemporâneos (representados, nesse caso, por Verlaine), os sintomas de uma "crise dolorosa" derivada, ao menos em parte, da chamada "emancipação do verso".

Pode-se objetar que essa emancipação - tal como costuma ocorrer com o campo semântico da liberdade, frequentemente associado à noção de verso livre - é parcial, dizendo respeito apenas a uma certa exigência técnicoformal, a contagem das sílabas poéticas. Não obstante, ela assinala, do ponto de vista da história literária francesa, o rompimento do chamado movimento simbolista (dentro do qual se encontrava, ainda uma vez, Verlaine) em relação aos poetas do Parnasse, sendo estes ligados a uma versificação mais tradicional e rigorosa. 0 quadro se torna ainda mais complexo, quando se leva em conta que Mallarmé sempre recusou o título de poeta simbolista e por vezes se designou como parnasiano, conforme recordam Ruppli e Thorel-Cailleteau (2005: 186). Além disso, ainda segundo essas autoras (2005: 188), “[...] em Crise de vers, ele discerne três maneiras, graduais, do verso livre, das quais a segunda consiste em manejar o alexandrino de modo que 'se toque pudicamente nele ou se jogue em seu entorno', o que acaba por designar sua própria maneira"7.

Pensamos que, por mais paradoxais e multifacetadas que se apresentem ao leitor, tais manifestações constituem sintomas de uma mesma e profunda crise, atrelada, desde o título do célebre texto contido em Divagations, à questão do verso. É infeliz, nesse sentido, que a análise empreendida por Ruppli e Thorel-Cailleteau não se detenha, no capítulo mencionado, sobre Um lance de dados, no qual, a rigor, nem se pode falar em versos. Ainda assim, cremos ser possível estender algumas das reflexões desenvolvidas pelas estudiosas ao

\footnotetext{
7 « Au reste, dans Crise de vers, il cerne trois manières, graduées, du vers libre, dont la seconde consiste à manier l'alexandrin de sorte qu'on ' $y$ touche pudiquement ou se joue alentour', ce qui revient à désigner sa propre manière ».
}

TradTerm, São Paulo, v.36, novembro/2020, p. 23-46 www. revistas.usp.br/tradterm 
poema em pauta, sempre pelo viés da crise, vocábulo que, lembremos de passagem, partilha seu radical com crítica.

Não consideramos ser necessário esboçar, aqui, uma espécie de paráfrase de Um lance de dados, intento que, de resto, já foi realizado de maneira muito competente por Álvaro Faleiros (2017: 30-39), em parte do texto introdutório à sua tradução. Porém, em paralelo ao que fizemos com o prefácio desse poema, convém realçar algumas de suas linhas de força, concentrando a atenção sobre certas possibilidades de leitura calcadas sobre a espécie particular de espaço por ele proposta, em que tem lugar e entra em crise a palavra escrita.

Diversos comentadores puseram ênfase sobre as figurações do Número, do cômputo, da matemática em Um lance de dados, figurações essas que já se evidenciam na imagem dos dados e se materializam textualmente em segmentos como "hors d'anciens calculs" e “l'unique Nombre qui ne peut pas/ être un autre" (MALLARMÉ 2003: 426-427). Nesses casos, via de regra, o dado numérico é aproximado da discussão sobre o acaso, o qual não pode jamais ser abolido, mesmo que se procedo a um “compte total en formation” (MALLARMÉ 2003: 441). É preciso recordar, contudo, o fato simples e primordial de que esse compte se faz com palavras - o material pouco nobre de que dispõe o poeta , e também por isso está sujeito à queda, ao fracasso, ao naufrágio. Ressurge assim, à tona, a imagem da "plume solitaire éperdue” (MALLARMÉ 2003: 432), não raro associada ao Hamlet shakespeariano, e que metaforiza o ícone mesmo do escrever, embora esteja distanciada de seu agente, isto é, de uma mão humana. Aliás, tal pluma se encontra rodeada de brancos, como se cercada de silêncios, no canto superior esquerdo de uma das páginas do poema: posição que se revela deveras sugestiva, se seguirmos certa análise da espacialidade sugerida por Faleiros (2017: 46), em trechos como “[e]ste espaço superior, na folha esquerda é, ao longo do poema, ocupado por termos como: Le maître; plume solitaire; issu stellaire; altitude [...], todos termos mais ligados aos céus do que às profundezas".

Essa dramatização da altura, no espaço gráfico-visual constituído pelo texto sobre a unidade da Página, opõe-se à simbolização do que é baixo, inferior: 
[...] o termo gouffre aparece duas vezes, em caracteres minúsculos, em páginas centrais e, em ambas as vezes, na parte inferior, à direita. Esses finais de página são, exceto na última, ocupados por termos como: fond naufrage, profondeur; tempête; brumes; parages du vague. (FALEIROS 2017: 47).

Tal sutileza, acertadamente assinalada pelo tradutor, lança um foco de luz sobre um procedimento composicional relevante em Um lance de dados, que se baseia no encontro das potencialidades semânticas de determinados termos com o lugar concreto que ocupam na página. Outrossim, esse procedimento está menos associado, a nosso ver, a uma "matemática da composição" - entendida como uma espécie de cálculo objetivo e absolutizante - do que a um agenciamento da crise do verso no espaço composicional construído pelo poeta. Assim, a queda da pluma - "choit/ la plumel rythmique suspens du sinistre" (MALLARMÉ 2003: 437) - conota a crise da escritura e a dramatiza como movimento orientado da região esquerda superior da página rumo ao canto inferior direito, num itinerário que coincide com a direção de leitura da maioria das línguas ocidentais, aí incluído o francês. Nesse sentido, o poema é sem dúvidas fruto da perquirição de e sobre a linguagem de que falavam Ruppli e Thorel-Cailleteau, mas é igualmente a dramatização da crise dessa linguagem em um espaço preciso, o da página ou, se quisermos, aquele em que tem lugar a escritura. Explica-se dessa forma, também, o destaque dado às diferenças dos caracteres tipográficos do poema, “entre o motivo preponderante, um secundário e adjacentes”, que ditam "sua importância na emissão oral e a disposição na pauta, média, no alto, embaixo da página” (MALLARMÉ 2017: 87).

0 que pretendemos salientar com essa breve digressão sobre a importância imagética da dimensão escritural de Um lance de dados é o fato de que, embora presente de modo sistemático, o imaginário numérico termina por não resolver definitivamente a equação, já que se mantém uma zona de ambiguidade e opacidade que, de nosso ponto de vista, advém necessariamente do plano linguístico da obra. É por meio desse viés que pensamos ser possível levantar algumas ressalvas abalizadas à tradução de Haroldo de Campos, 
buscando retomar o fio que leva de seu projeto tradutório mais amplo até determinadas soluções precisas mobilizadas por esse tradutor.

\section{3.}

Em 1974, no Brasil, veio à luz um volume intitulado Mallarmé, produzido por Décio Pignatari, Augusto e Haroldo de Campos, contendo, em meio a rico material crítico e tradutório, a tradução de Um lance de dados assinada por este último. 0 interesse do grupo concretista pelo poeta francês, contudo, era bem mais antigo, conforme escreve Haroldo de Campos (2010: 13) na "Nota introdutória": "[m]ais de 20 anos de trabalho em conjunto [...] conduzem a este nosso, agora, Mallarmé [...]: um Mallarmé que vem sendo trigerido desde os anos 50 completa agora o quadrante da circunviagem: paideuma, quadrívio". A apresentação do autor estudado e traduzido remonta a uma escolha também de ordem crítica e criativa, fazendo eco às ideias de Haroldo contidas no já citado artigo "Da tradução como Criação e como Crítica", publicado pela primeira vez em 1963. Assim, a inversão constitutiva daquela edição - que transforma o trio de concretistas em autores de Mallarmé - é sintomática, na medida em que dá a ver uma apreensão muito particular, orientada e necessariamente redutora do poeta em questão.

Em realidade, o Mallarmé produzido pelos concretos integra um paideuma erigido sob o signo do quadrívio, já que conta também com Joyce, Pound e cummings. A simples eleição desses nomes já evidencia a ênfase posta sobre a dimensão inventiva da linguagem poética, num viés de leitura que traz à mente certos grupos vanguardistas do início do século XX. Desse modo, não deve causar estranhamento que a apreensão concretista do poeta francês embase amplamente o projeto de Haroldo de Campos, fazendo-se presente em "Por uma poética sincrônica" e em outros textos de $A$ arte no horizonte do provável (1969) - conforme já lembrado por Siscar em trecho citado -, assim como no manifesto "Da fenomenologia da composição à matemática da 
composição", publicado inicialmente em 1957, e que constitui um dos alicerces teóricos da práxis concretista. Registremos de passagem que, nesse texto, Um lance de dados é mobilizado para justificar e exemplificar o fato de que "a passagem da fenomenologia da composição à matemática da composição coincide com outra passagem: a do organo-fisiognômico para o geométricoisomórfico" (CAMPOS 2006: 135). Ademais, no que diz respeito mais precisamente à atividade tradutória de Haroldo, Jacques Derrida afirma (2015), num texto encomiástico dedicado ao amigo brasileiro, que não é possível dissociá-la do poema de Mallarmé, intertexto que também emerge no discurso do pensador franco-argelino.

Não devemos nos ocupar, contudo, apenas com aspectos do projeto haroldiano, pois assim poderíamos recair numa espécie de crítica de princípios; nessa direção, pode ser enriquecedora a análise e o cotejo de algumas passagens das traduções brasileiras de Um lance de dados. Um exemplo inicial se concentra exatamente em torno do vocábulo vers, que aparece duas vezes ao longo do poema, nestas passagens, situadas aproximadamente no início da porção mediana e em sua parte final: "le viellard vers cette conjonction suprême avec la probabilité" e "vers / ce doit être/ le Septentrion aussi Nord" (MALLARMÉ 2003: 428-441, grifo nosso).

A partir do que já discutimos neste estudo, está claro que a segmentação de trechos desse poema é bastante problemática, uma vez que ele desloca e transforma o entendimento convencional do verso, repropondo-o num ambiente em que a visualidade da página assume importância vital. Além disso, seria possível argumentar que ambas as ocorrências citadas de vers apresentam sentido prepositivo - algo como as preposições portuguesas "para", "rumo a" ou "em direção a" -, não possuindo, pois, qualquer relação com o tema desta discussão. Em que pese essa possibilidade de leitura, é interessante acompanhar as soluções adotadas pelos dois tradutores brasileiros para tais passagens:

I.

o velho versus esta conjunção suprema com a probabilidade (trad. Haroldo de Campos, s.p.) 
o velho a versar para esta conjunção suprema com a probabilidade (trad. Álvaro Faleiros, p. 96)

II.

versus

deve ser

o Setentrião também Norte

(trad. Haroldo de Campos, s.p.) versar para

deve ser

o Setentrião também Norte (trad. Álvaro Faleiros, p. 109)

Nesses dois segmentos, cada tradutor adota uma solução própria e distinta para o vocábulo original vers - a qual se mantém quase sem alterações nessas ocorrências -, ao passo que ambos traduzem igualmente os sintagmas do entorno. Esse fato já seria per se digno de nota, mas ganha mais relevância quando se percebe que nenhum tradutor resolveu a palavra vers de modo literal, isto é, empregando as aludidas preposições: felizmente, dispomos de seus testemunhos sobre essa dificuldade particular. Escreve Haroldo de Campos (2010: 130-142): “[t]raduzi vers por versus no sentido latino 'em direção a', o que me permitiu preservar a ambiguidade com 'verso' (do lat. versus, sulco, renque de árvores, linha escrita, verso)” e, posteriormente, “[p]elas mesmas razões pelas quais adotei a fórmula o velho versus esta conjunção suprema [...], emprego aqui a palavra latina versus (com o sentido de 'em direção a' [...]). [...] Sonoramente, pude estabelecer a sequência VERSUS/ dEVE SER [...]”.

Já de início, essa escolha nos parece curiosa, visto que Campos opta por traduzir um vocábulo francês por uma expressão latina, pretendendo com isso preservar uma ambiguidade, de fato existente no original, entre as acepções substantiva e prepositiva de vers. Não se pode negar, entretanto, a qualidade sonora da "sequência" produzida nessa primeira tradução. Álvaro Faleiros, por sua vez, anota:

É importante salientar que a questão suscitada pela tradução de vers e a preocupação de Haroldo de Campos em encontrar um termo polissêmico ilustram aquela que é, provavelmente, a maior dificuldade enfrentada por um tradutor de poemas: o signo duplo. Num texto linear, na maioria dos casos, pode-se, 
no momento de se traduzir a preposição vers, optar, sem grandes danos, pelas preposições "rumo" ou "para"; entretanto, em Um Lance de Dados, poema que introduz uma importante ruptura com o próprio conceito de verso, por mais que o uso de vers seja sintaticamente com função prepositiva, o apagamento dessa ambiguidade representa um problema considerável. (FALEIROS 2017: 55)

Após essas considerações, o tradutor explicita as razões de sua própria escolha:

Diante do impasse, procurei uma solução que não exigisse do leitor um conhecimento do latim, mas que, de alguma maneira, produzisse ambiguidade análoga [...]. 0 verso "versar" representa um acréscimo sintático deformante, entretanto, significa tanto "passar de um local para outro" quanto “versejar". (FALEIROS 2017: 55)

Essa tentativa de responder ao impasse - preservando a ambiguidade da expressão e não exigindo do leitor o conhecimento da língua latina - ilustra com justeza, de nossa perspectiva, o projeto retradutório deste último, que se constrói sobre determinados “contrapontos à sinfonia haroldiana”, conforme um dos subtítulos de sua apresentação ao volume, intitulada "Refrações sobre Um Lance de Dados de Mallarmé" (FALEIROS 2017: 29-58). Desse modo, em contraposição à postura assumida por Campos, que considera a maior parte das soluções por ele mesmo adotadas como "achados" ou, no mínimo, tentativas bem-sucedidas, Faleiros (2017: 55) manifesta a consciência de que incluiu "um acréscimo sintático deformante", realizando com isso apenas “mais essa tentativa à história da tradução de vers; esse signo polissêmico que habita o universo literário".

Ora, tal exemplo nos parece corroborar o fato, assinalado por Álvaro Faleiros na orelha à edição de sua tradução de Um lance de dados, de que a poética neobarroca de Haroldo de Campos "acrescentava sinuosas dobras ao já difícil texto mallarmeano levando, em alguns casos, até a contrassensos”. Estes ficariam a cargo, no caso aqui discutido, do segmento "o velho versus esta conjunção suprema com a probabilidade”, o qual, ainda nas palavras de Faleiros (2017: 55), “acrescenta um contrassenso, pois modifica o sentido ao introduzir 
no texto em português um termo latino com um significado que não possui em português". No limite, portanto, a erudita solução haroldiana poderia levar a uma interpretação errônea do trecho, ao inserir um sentido de oposição (presente no uso português da palavra versus) que inexiste no original.

Não pretendemos com isso, todavia, fazer uma espécie de crítica moralista, em que a postura assumida pelos tradutores em seus discursos prevaleça sobre as traduções; tampouco queremos julgar estas com base em tão poucos exemplos. Menos ainda, gostaríamos de sugerir que o modo como Campos e Faleiros traduzem vers faz reverberar plenamente a noção de verso (ou de sua crise) mobilizada por Mallarmé. No entanto, cremos positivamente que tais aspectos, quando lidos de maneira conjunta e em diálogo com outras esferas do fenômeno tradutório, podem contribuir para uma leitura crítica mais responsável das traduções brasileiras de Um lance de dados.

Assim, retornemos ainda uma vez aos exemplos trabalhados. 0 primeiro (no original, “le viellard vers cette conjonction suprême avec la probabilité”) bem poderia ser aproximado da "mistura de prosa e verso livre" já referida por Siscar (2017: 22), na medida em que mantém certo fio sintático e excede notavelmente o número de sílabas poéticas convencionalmente encontrado no verso metrificado francês, que raramente ultrapassa doze ou quatorze sílabas. Já o segundo ("vers/ ce doit être/ le Septentrion aussi Nord") apresenta segmentos de uma, quatro e oito sílabas poéticas, emulando, na própria ocupação do espaço gráfico-visual da página - algo que só pode ser verdadeiramente observado quando o trecho está incorporado ao poema -, a disposição fragmentária e constelar das sete estrelas nórdicas da Ursa Maior, implícitas na referência ao Setentrião.

Diante de uma irregularidade de tal ordem - que excede, a nosso ver, os exemplos trabalhados por Paulo Henriques Britto $(2011,2014)$ em artigos em que reflete sobre uma tipologia do verso livre -, não é possível recorrer à cristalização definitiva de uma "fôrma” capaz de corresponder plenamente às necessidades da "nova forma" constituída por Um lance de dados. Nesse sentido, pensamos ser vão o propósito de realizar um "compte total” das sílabas poéticas do poema e de suas traduções como procedimento de aferição das qualidades tradutórias implicadas em cada caso. Isso porque tal expediente 
conduziria necessariamente a uma concepção convencional do verso enquanto repositório de unidades métricas, ou ainda a uma tentativa de estabelecer um rol dos tipos de verso livre, este entendido como forma passível de ser identificada e categorizada, ainda que com base em critérios diversos ${ }^{8}$.

Desse modo, pensamos que a maneira mais responsável de considerar a questão do verso no poema de Mallarmé e em suas traduções consiste justamente em tratá-la como crise, ou seja, enquanto problema irresolvido, opaco e, por isso mesmo, capaz de suscitar produtivamente uma multiplicidade notável de leituras possíveis. É, pois, nesse sentido que preferimos o esforço de legibilidade - o qual não se confunde com reducionismo ou clareamento levado a cabo por Álvaro Faleiros, ao manejo excessivamente orientado da atividade crítica e criativa de Mallarmé operado por Haroldo de Campos.

Ainda naqueles exemplos, ao traduzir vers como “(a) versar para”, o primeiro não promove apenas uma suposta facilitação da leitura, ao contraporse à necessidade de que o leitor conheça a língua latina, nem tampouco simplesmente evita o contrassenso identificado na fórmula forjada pelo segundo. Mais do que isso, em sua tradução, Faleiros favorece a percepção de uma sintaxe existente em ambos os trechos, a qual leva "le viellard" em direção a essa "conjonction suprême avec la probabilité” (uma das figurações da ideia de verso, aqui entendido como cálculo probabilístico), no primeiro caso, e descreve o movimento descendente (quase do verbo verter) entre os pequenos segmentos verbais do segundo trecho. De maneira oposta, a tradução de Haroldo aparenta obstruir o movimento da sintaxe, ao interpor a preposição versus, que apenas de forma muito mediada pode realizar seu sentido prepositivo latino de "em direção a"

\footnotetext{
${ }^{8}$ Embora tenhamos recusado o método de contagem silábica para tratar de Um lance de dados, reconhecemos que esse poema pode ser aproximado, pelo menos do ponto de vista estilístico, de algumas características de uma modalidade do verso livre estabelecida por Britto (2011). Escreve o crítico e tradutor: "[o]utro caminho deve ser seguido com relação ao novo verso livre, tipicamente curto e marcado pelo enjambement em sua forma mais radical, que foi desenvolvido em língua inglesa a partir de William Carlos Williams e E. E. Cummings. [...] Não há uma fórmula geral para a análise de poemas desse tipo, mas, entre os componentes a serem considerados, podemos destacar o verso com[o] elemento gráfico, delimitado na página pela quebra de linha, e o grupo de força [...]. Nesse tipo de verso, por vezes os elementos visuais têm importância: a fonte empregada, a disposição das palavras e letras na página" (BRITTO 2011: 132).
} 
É certo que poderíamos objetar, com Thelma M. Nóbrega (2007), que o método tradutório de Haroldo de Campos - por ele chamado, por vezes, de transcriação - "significava acima de tudo uma postura de fidelidade, ou de hiperfidelidade", o que corresponde, segundo a autora (2007: 250-251), a "uma literalidade e uma aderência ao signo". Tais propósitos teriam ressonância, no caso de Um lance de dados, sobretudo no critério da "retomada etimológica", conforme proposto por Haroldo (2010) e posteriormente lembrado por Faleiros (2017). Ao analisar a tradução haroldiana, escreve a autora:

\begin{abstract}
Ao propor "pensa" para "penché", ele [Haroldo de Campos] parte do latim pendere (pender, ponderar, pesar), que está na raiz do verbo francês pencher, causando em português uma ambiguidade entre o adjetivo "pensa" e o verbo "pensar". "Le viellard vers cette" ficou "o velho versus esta", já que versus, no sentido latino, significa "em direção a", recuperando a ambiguidade do francês vers, que vem do latim versus (linha escrita, verso). Outro exemplo é “êxito", próximo do latim exitus, para "issu” (saída). (NÓBREGA 2007: 252)
\end{abstract}

Por meio dessa exemplificação, torna-se nítido que, para Nóbrega, a retomada etimológica via língua latina não constitui algo problemático, e sim uma estratégia lícita e certeira para aderir à literalidade do texto original, em um exercício de hiperfidelidade. Antes de discutirmos, ainda uma vez, seus exemplos, convém atentar para o fato de que, segundo a autora (2007: 251), "Haroldo relacionou o método ideogrâmico, que Pound extraiu de Fenollosa, ao Coup de dés, poema cósmico-visual de Mallarmé”. Assim, em suas traduções, "Haroldo radicaliza o método ideogrâmico, aproximando-o da paixão etimológica de Mallarmé e dos precursores deste [...]" (NóBREGA 2007: 252).

De nosso ponto de vista, propomos que tal "método ideogrâmico" - que consiste numa apreensão deveras particular da obra mallarmeana, novamente relacionada às vanguardas e à leitura de Ezra Pound - pode explicar, ao menos em parte, a impressão de imobilismo e intransitividade por nós identificada nos trechos da tradução de Campos. Assim, haveria nesta uma ambição de extrair do signo (unidade que se confunde, nesse caso, antes com o vocábulo do que com a frase ou a página) uma espécie de evidenciação plena do sentido, como se a palavra versus fosse capaz de dar a ver, por si só, toda a ambiguidade 
contida no francês vers. Trata-se, sem dúvida, de uma visão ambiciosa das potencialidades de sentido manejadas pela tradução; no entanto, tal propósito se traduz, a nosso ver, em procedimentos bastante questionáveis. $\mathrm{E}$, uma vez que para Haroldo de Campos as atividades de tradução, criação e crítica estão intrinsecamente ligadas, não seria impossível aproximar tal intenção - que poderíamos denominar, com Nóbrega, de método ideogrâmico -, ainda que de passagem, do anseio pela "verbivocovisualidade" como aspecto fundante do signo poético em parte do projeto concretista?.

Por fim, se quiséssemos recorrer a uma analogia de ordem cósmica, tudo se passa como se, na tradução de Um lance de dados assinada por Campos, fossem dados relevo e significância a cada uma das estrelas, com forte tendência ao isolamento, ao passo que, na tradução de Faleiros, a ênfase estivesse nos interstícios e movimentos existentes entre os corpos celestes, em seu pendor para formar constelações. É eloquente, ainda nesse sentido, retomar o último exemplo mobilizado por Nóbrega na citação anterior, o qual pode ser esquematizado do seguinte modo:

C'ÉTAIT

issu stellaire
FOSSE

êxito estelar
FOSSE

saída estelar

(original) (trad. Haroldo de Campos, s. p.) (trad. Álvaro Faleiros, p. 104)

Embora novamente precisemos incorrer no problema da segmentação, os trechos acima se revelam significativos, em primeiro lugar porque exibem uma diferença notável no que diz respeito à tradução do vocábulo francês “issu”, que corresponde a "êxito" na primeira e a "saída” na segunda das traduções". O argumento haroldiano para sua opção é, ainda uma vez, de natureza etimológica: “[e]scolhi êxito tanto pela configuração sonora, como pela proximidade etimológica, do lat. exitus (saída), mantida no inglês atual exit

\footnotetext{
9 O termo "verbivocovisual" foi retirado de Finnegans Wake, romance de James Joyce, e aproveitado de modo sistemático pelo grupo concretista. Para uma análise mais aprofundada da noção, remetemos a Bernardes Campos (2019).
} 
(issue vem do ant. francês issir, sair)" (CAMPOs 2010: 137). Contra essa solução, Álvaro Faleiros elenca três objeções, das quais destacamos a terceira:

Em terceiro, e aí reside a questão etimológica, se issu vem do antigo francês issir, bastante próximo de "sair" e do substantivo "saída", o termo "êxito" é etimologicamente próximo de quê? Do latim? Do inglês? De todos os significados que Haroldo de Campos dá para issu, o único que tem conotação de conquista é "êxito"; o que acrescenta uma dimensão de vitória, que não condiz com o "Hamlet poeta" que habita o poema, para quem a constelação é saída, mas não necessariamente vitória [...]. (FALEIROS 2017: 53-54)

Tal contra-argumento nos parece inquestionável, pois desmistifica uma suposta retomada etimológica que, mesmo recorrendo a outros idiomas, revelase insatisfatória, se não propriamente incorreta. Consideramos ainda mais notável a nuance semântica entre "êxito" e "saída": embora, nesse trecho, Faleiros se limite a tratá-la no âmbito da referência ao Hamlet evocado por Campos (2010: 120) em suas notas e que habitaria o poema mallarmeano, defendemos que ela é sintomática de boa parte das reflexões que desenvolvemos até aqui. Elegendo, dentre as acepções possíveis - "Issu,e significa: 'procedente', 'descendente', 'oriundo'; e ainda: 'saída', 'desembocadura', 'êxito', 'resultado', 'fim' [...]” (CAMPos 2010: 137) -, a única que tem um sentido positivo explícito, de vitória, Haroldo parece pretender dar ao poema um tom heroico, glorioso, que não apenas contradiz seu sentido geral, como também se opõe à experiência da crise vivenciada por Mallarmé no espaço crítico por ele inventado. Nesse sentido, assim como em termos fônicos ou mesmo de um viés da linguística diacrônica, a solução adotada nesse exemplo por Faleiros se mostra mais adequada, já que oferece somente uma saída para a referida crise, não pretendendo necessariamente ter êxito diante dela.

Tampouco nós pretendemos resolvê-la, até porque, para continuar produtiva, tal crise deve ser mantida enquanto tal. Igualmente, não pretendemos asseverar um juízo crítico das traduções brasileiras de Um lance de dados que funcione de todos os pontos de vista - tarefa de resto impossível -, muito embora, sob a perspectiva aqui delineada, tenha ficado nítida nossa 
preferência. Por fim, para encerrar estas divagações, fazemos nossas as palavras de Marcos Siscar, ao final do ensaio já citado ao longo destas páginas:

Responder à estranheza de Mallarmé, num sentido que interessa a essa outra virada de século prenhe de naufrágios $(\mathrm{e}$, ao mesmo tempo, sequiosa por abandonar as tensões da crise, por resolvê-la enfim), seria dar uma resposta poética à aceitação incrivelmente rápida da ideia histórica do fim da história. Ainda há lugar para Mallarmé, hoje? Retraduzir Un Coup de dés terá sido o lance de dados. (SISCAR 2017: 26) 


\section{Agradecimentos}

Agradecemos à Prof ${ }^{a}$. Dra ${ }^{a}$. Sandra M. Stroparo (UFPR), que, além de ter ministrado uma instigante disciplina de pós-graduação na FFLCH/USP em agosto de 2018 ("Tradução e verso livre na França do Século XIX”) e indicado diversos textos para leitura, leu com atenção e generosidade a primeira versão deste artigo.

\section{Referências bibliográficas}

BERNARDES CAMPOS, R. Entre vivas e vaias: a visualidade concreta de Augusto de Campos. 2019. 153f. Tese de doutorado em Literatura - Instituto de Letras da Universidade de Brasília, Brasília, DF.

BRITTO, P. H. Para uma tipologia do verso livre em português e inglês. Revista Brasileira de Literatura Comparada, Niterói, n. 19, v. 1, 2011, p. 127144.

BRITTO, P. H. O natural e o artificial: algumas reflexões sobre o verso livre. eLyra: Revista da Rede Internacional Lyracompoetics, Porto, n. 3, v. 1, 2014, p. 27-41.

Campos, A.; Campos, H.; Pignatari, D. Mallarmé. São Paulo: Perspectiva, 2010 [1974].

CAMPOS, H. A arte no horizonte do provável. São Paulo: Perspectiva, 1972 [1969].

CAMPOS, H. Da tradução como Criação e como Crítica. In:CAmpos, H . Metalinguagem \& outras metas. São Paulo: Perspectiva, 1974, p. 31-48.

CAMPOS, H. Da fenomenologia da composição à matemática da composição. In: CAmpos, A.; CAmpos, H.; PIgnATARI, D. Teoria da poesia concreta: textos críticos e manifestos 1950-1960. Cotia, SP: Ateliê Editorial, 2006 [1965], p. 133-136.

DerRIDA, J. Chaque fois, c'est-à-dire, et pourtant, Haroldo.... Revista Cisma edição especial Haroldo de Campos, ano IV, 2015, p. 16-18.

FALEIROS, A. Refrações sobre Um Lance de Dados de Mallarmé. In: MALLARMÉ, Stéphane. Um Lance de Dados. Introdução, organização e tradução Álvaro Faleiros. Cotia, SP: Ateliê Editorial, 2017, p. 29-58.

FALEIROS, A.; MATTOS, T. A retradução de poetas franceses no Brasil: de Lamartine a Prévert. São Paulo: Rafael Copetti Editor, 2017.

Gullar, F. Fotografia de Mallarmé. In: Gullar, F. Muitas vozes. Rio de Janeiro: José Olympio, 1999, p. 138-139.

MALLARME, S. Igitur. Divagations. Un coup de dés. Nouvelle édition, présentée et 
établie par Bertrand Marchal. Paris: Gallimard, 2003.

MALLARMÉ, S. Um Lance de Dados. Introdução, organização e tradução Álvaro Faleiros. Cotia, SP: Ateliê Editorial, 2017 [2013].

MEdeIROS, S. Prefácio à $2^{\mathrm{a}}$ edição: não houve naufrágio. In: MALLARMÉ, S. Um Lance de Dados. Trad. Álvaro Faleiros. Cotia, SP: Ateliê Editorial, 2017, p. 9-10.

NóBREGA, T. M. Transcriação e hiperfidelidade. Cadernos de Literatura em Tradução, São Paulo, n. 7, v. 1, 2007, p. 249-256.

NóbreGA, T. M; TÁPIA, M. (org.). Haroldo de Campos - Transcriação. São Paulo: Perspectiva, 2013.

Ruppl, M.; Thorel-Callleteau, S. Mallarmé: la grammaire et le grimoire. Génève: Ed. Droz, 2005.

SISCAR, M. Traduzir Mallarmé é o lance de dados. In: Mallarmé, S. Um Lance de Dados. Introdução, organização e tradução Álvaro Faleiros. Cotia, SP: Ateliê Editorial, 2017, p. 11-28.

Recebido em: 19/08/2020

Aceito em: 29/10/2020

Publicado em novembro de 2020 